\title{
Immunization - Guidelines and Applications: Sheeja Sugunan (Ed)
}

\section{Published by Paras Medical Publisher; Hyderabad, India; 2nd Edition; 2020; \\ ISBN: 978-81-8191-519-1}

\section{Anju Aggarwal ${ }^{1}$ (C)}

Received: 15 July 2020 / Accepted: 15 July 2020 / Published online: 25 July 2020

(C) Dr. K C Chaudhuri Foundation 2020

Immunization is a cost effective way of bringing down the disease burden. Students and practitioners need a ready reckoner to know about vaccines. This book by Sheeja Sugunan covers basic immunology and need for vaccines in a very simple way. Handling of vaccines and individual vaccines have been covered well. There are 4-5 questions in the end so that one understands the logic behind a particular recommendation.

Though the vaccine schedules are ever changing; why a particular schedule is followed and scientific bases behind these particular schedules could have been further discussed. Details of strains and potency of components of vaccines needs to be included the last table. A little information about reporting of AEFI would be appreciated. Overall, a handy book to read for both undergraduate and postgraduate students and practitioners. Idea of a session on 'think a bit' is new. This is addressing important concerns and controversies in a scientific manner. Important references have been included in the last. Overall an interesting book to read.

Publisher's Note Springer Nature remains neutral with regard to jurisdictional claims in published maps and institutional affiliations.

Anju Aggarwal

aanju67@gmail.com

1 Department of Pediatrics, University College of Medical Sciences and Guru Tegh Bahadur Hospital, New Delhi India 